\title{
Association of Retinal Layer Thickness With Cognition in Patients With Multiple Sclerosis
}

Sharon Jean Baetge, MSc, Michael Dietrich, PhD, Melanie Filser, MSc, Alina Renner, MSc, Nathalie Stute, MSc, Marcia Gasis, MSc, Margit Weise, MSc, Klaudia Lepka, PhD, Jonas Graf, MD, Norbert Goebels, MD, Hans-Peter Hartung, MD, Orhan Aktas, MD, Sven Meuth, MD/PhD, Philipp Albrecht, MD*, and Iris-Katharina Penner, $\mathrm{PhD}^{*}$

Neurol Neuroimmunol Neuroinflamm 2021;8:e1018. doi:10.1212/NXI.0000000000001018

\section{Abstract \\ Objective}

Retinal layer thickness (RLT) measured by optical coherence tomography (OCT) is considered a noninvasive, cost-efficient marker of neurodegeneration in multiple sclerosis (MS). We aimed to investigate associations of RLT with cognitive performance and its potential as indicator of cognitive status in patients with MS by performing generalized estimating equation (GEE) analyses.

\section{Methods}

In this cross-sectional study, patients with at least mild signs of cognitive impairment were examined by OCT as well as by the Brief International Cognitive Assessment for MS and tests assessing attention and executive functions (Trail Making Test [TMT] A and B). Associations of these factors were investigated using GEE models controlling for demographic and diseaserelated factors and correcting for multiple testing.

\section{Results}

A total of 64 patients entered the study. In the final sample $(n=50[n=14$ excluded due to missing data or drop-outs]; $n=44$ relapsing-remitting MS and $n=6$ secondary progressive MS, mean Expanded Disability Status Scale score $=2.59[\mathrm{SD}=1.17]$, disease duration [median] = 7.34 [interquartile range $=12.1$ ]), 36.0\% were cognitively impaired. RLT of the macular retinal nerve fiber layer was associated with performance in TMT-B $(\beta=-0.259)$. Analyses focusing on the upper and lower tertile of RLT additionally revealed associations between macular ganglion cell-inner plexiform layer and TMT-B and verbal short-term memory and learning, respectively.

\section{Conclusion}

In patients with MS, at less advanced disease stages, RLT was especially associated with cognitive flexibility promoting OCT as a potential marker advocating further extensive neuropsychological examination.

\author{
Correspondence \\ Prof. Dr. Penner \\ iris-katharina.penner@ \\ uni-duesseldorf.de
}




\section{Glossary}

BICAMS = Brief International Cognitive Assessment for MS; BVMT-R = Brief Visuospatial Memory Test-Revised; CI = cognitive impairment; EDSS = Expanded Disability Status Scale; GCIPL = ganglion cell-inner plexiform layer; GEE = generalized estimating equation; $\mathbf{I Q R}=$ interquartile range; $\mathbf{m R N F L}=$ macular retinal nerve fiber layer; $\mathbf{M S}=$ multiple sclerosis; OCT = optical coherence tomography; $\mathbf{O N}=$ optic neuritis; $\mathbf{P R N F L}=$ peripapillary retinal nerve fiber layer; $\mathbf{R L T}=$ retinal layer thickness; RRMS = relapsing-remitting MS; SDMT = Symbol Digit Modalities Test; VLMT = Verbaler Lern-und Merkfaehigkeitstest.

For patients with multiple sclerosis (MS), cognitive impairment $(\mathrm{CI})$ can be a prominent symptom of the disease, even at early stages. ${ }^{1}$ Despite the need for regular neuropsychological assessments to identify $\mathrm{CI}$ as early as possible, ${ }^{2,3}$ appropriate examinations are not yet integrated in established monitoring standards of clinical care.

The informative value of current biomarkers in MS diagnostics such as conventional MRI sequences is rather limited in accurately reflecting direct associations of neuropsychological function and potential underlying substrates, particularly in early stages of the disease. ${ }^{4,5}$ In the last decades, the method of retinal optical coherence tomography (OCT) was introduced to measure and clinically monitor the degree of neurodegeneration in the retinae of patients with MS, complementary to brain MRI. Within this research, inner retinal layer thicknesses (RLTs) assessed by OCT were found to be altered independently of a history of optic neuritis $(\mathrm{ON})$ in $\mathrm{MS}^{6,7}$ suggesting neurodegenerative processes. ${ }^{8-10}$ These processes might not only affect the retinae but also relevant cerebral structures and could therefore influence cognitive outcomes. Because of the feasible, costefficient, and convenient application of OCT in clinical settings, RLT might bear the potential to be a valuable monitoring indicator for impaired cognitive performance providing the impulse for an extensive neuropsychological evaluation where necessary.

To our knowledge, systematic examinations of state-of-the-art neuropsychological instruments in relation to a comprehensive set of currently discussed OCT parameters, while accounting for demographic and disease-related factors, have rarely been conducted. Importantly, only few studies ${ }^{11-15}$ have included all tests of the Brief International Cognitive Assessment for MS (BICAMS), although it is considered the international gold standard to screen for CI in MS since 2012. ${ }^{16}$ The present study, therefore, aims at examining the relationship of RLT with cognitive performance in BICAMS and tests for attention and executive functions in ambulatory patients with mild to moderate clinical deficits to investigate the potential of OCT pointing toward CI. Data were derived from the baseline examination of a larger interventional study.

\section{Methods}

\section{Study Population}

The data entering the present study were obtained from the baseline data of a larger interventional study examining the effects of an exercise program and a computer-based cognitive program, respectively. Sixty-four patients diagnosed with relapsing-remitting MS (RRMS) or secondary progressive MS (SPMS) were consecutively included from October 2016 to September 2018. Participating patients were required to be at least 18 years old and fluent in German and to have an Expanded Disability Status Scale (EDSS) score $\leq 5.0$ as well as no current acute neurologic or psychiatric disorder (apart from MS). All patients were relapse free for at least 60 days. Furthermore, participants did not have severe, uncorrected visual or hearing impairment, known confounding ocular pathologies $^{17}$ or upper extremity difficulties that may have compromised the neuropsychological testing performance. Confirmation of MS diagnosis and the current EDSS were provided by documents of the treating neurologist, which were verified by 2 coauthors (O.A. and A.R.). All patients had to show at least mild to moderate $\mathrm{CI}$ in information processing speed at baseline reflected by an Symbol Digit Modalities Test (SDMT) z-score between -0.5 and -3.0 . Finally, the examined sample included 50 patients due to dropouts after the neuropsychological examination and exclusions based on a previous history of $\mathrm{ON}$ as depicted in figure 1 . The mean interval between neuropsychological testing and OCT was 1 month in which no disease-related changes occurred.

\section{Standard Protocol Approvals, Registrations, and Patient Consents}

All patients provided written informed consent and voluntarily participated in the study. Ethical approval for the study was given by the ethics committee of the Medical Faculty of the Heinrich Heine University Duesseldorf, Germany (study number: 5531R, registration-ID: 2016055083). Study procedures were conducted in accordance with the principles of the Declaration of Helsinki.

\section{Assessment and Measurement of RLT Using OCT}

The OCT methodology is reported in line with the Advised Protocol for OCT Study Terminology and Elements recommendations. ${ }^{18}$ Spectral domain OCT examination was performed for both eyes of each patient by trained operators of the Düsseldorf University Hospital using Heidelberg-Spectralis (Heidelberg Eye Explorer, version 1.9.10.0) under ambient light conditions as previously described. ${ }^{6}$ Investigators performing the OCT were blinded to the results of cognitive testing and the neuropsychological inclusion criterion. After quality control of the scans according to OSCAR-IB Consensus Criteria 
Figure 1 Flowchart

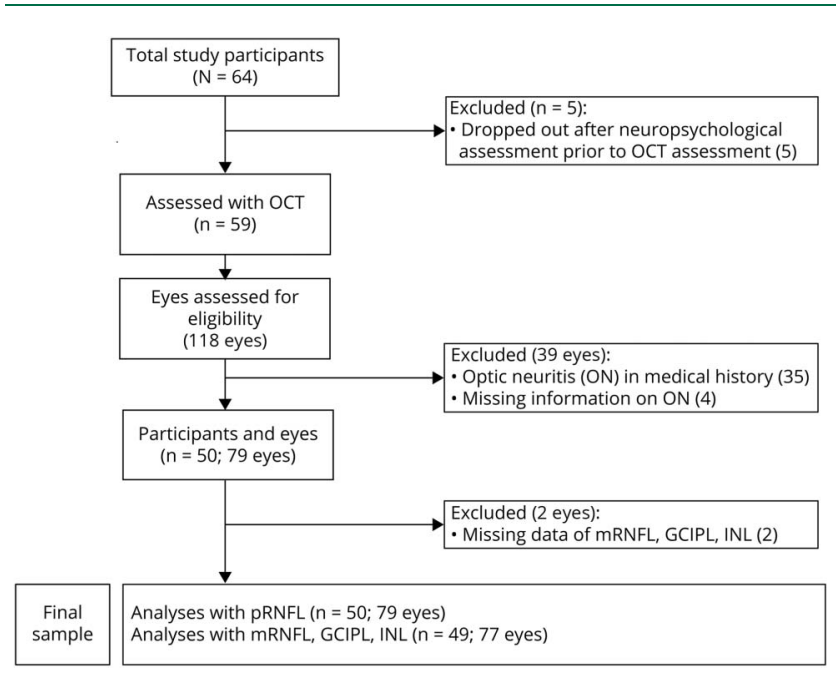

Study flowchart depicting exclusions, dropouts, and the final sample. Of 64 study participants, 59 underwent OCT. After quality control and excluding missing data and data of eyes having a history of ON or lacking information on ON, data of 79 eyes were included in analyses regarding pRNFL and data of 77 eyes in analyses with mRNFL, GCIPL, and INL, respectively. " $n$ " refers to the number of study participants. Numbers in brackets display the number of eyes. GCIPL = macular ganglion cell-inner plexiform layer; $I N L=$ inner nuclear layer; $\mathrm{mRNFL}=$ macular retinal nerve fiber layer; $\mathrm{OCT}=$ optical coherence tomography; $\mathrm{ON}=$ optic neuritis; $\mathrm{PRNFL}=$ peripapillary retinal nerve fiber layer.

for Retinal Quality Assessment, ${ }^{17,19}$ further processing was performed using automated segmentation, followed by manual correction of segmentation errors by a blinded investigator. For the process of quality control and manual correction, OCT data were pseudonymized beforehand. Information on a history of ON was obtained by interviewing each patient and verified by P.A. and M.W. reviewing medical records and OCT scans. Based on this, patients with bilateral $\mathrm{ON}$ were excluded from the sample (figure 1). In case of unilateral $\mathrm{ON}$, only the non-ON eye was included. If both eyes had not had previous ON, both eyes were included in the analysis. The mean thicknesses were calculated and statistically analyzed for the peripapillary retinal nerve fiber layer ( $\mathrm{pRNFL})$ from circular ring scans $\left(12.0^{\circ}[3.5\right.$ $\mathrm{mm}$ ] circle diameter). For macular RNFL (mRNFL), macular ganglion cell-inner plexiform layer (GCIPL) and inner nuclear layer (INL) mean thicknesses were obtained from $30^{\circ} \times 25^{\circ}$ volume scans using the 1-, 3-, and 6-mm ETDRS grid.

\section{Neuropsychological Assessment}

Study participants underwent an extensive neuropsychological assessment in the Cogito center comprising an initial interview, various questionnaires, and tests including the German version of the BICAMS ${ }^{16}$ as well as Trail Making Test (TMT) A and B to examine visual attention and cognitive flexibility. BICAMS covers the SDMT assessing information processing speed, the Verbaler Lern-und Merkfaehigkeitstest (VLMT, direct recall) for verbal short-term memory and learning, and the Brief Visuospatial Memory Test-Revised (BVMT-R) evaluating the visuospatial short-term memory and learning. During the initial interview, participants were surveyed regarding demographic and disease-related data. Trained research assistants and psychologists who performed the neuropsychological assessments were blinded to the results of the OCT examination. For the description of the examined sample, we defined $\mathrm{CI}$ as performance below the 5th percentile $(\mathrm{z}=-1.645$ or percentage range $=5$ in at least 1 of the BICAMS tests, respectively).

\section{Statistical Analyses}

Statistical analyses were performed using SPSS software (IBM SPSS Statistics version 26.0). We present descriptive statistics according to the nature of the data as means with SD, median with range and interquartile range (IQR), and percentages, respectively. To analyze associations of RLT and cognitive performance, separate generalized estimating equation (GEE) models were computed. This method was used to perform the analyses on eye level instead of subject level adjusting for intrasubject intereye correlations. Each GEE analysis was computed focusing on thickness of 1 retinal layer predicting one of the cognitive test outcomes under study while controlling for demographic and disease-related factors. These factors comprised age, educational level, sex, MS subtype, and disease duration and were selected based on theoretical aspects as partially seen in previous studies investigating cognitive performance and RLT., ${ }^{9,20-22}$ Beta coefficients were calculated using means and SDs. Scatterplots of each pair (RLT and cognitive test outcome) display the distribution of the data.

To further explore whether the comparison of extreme groups (patients with thinnest and thickest retinal layers) in the present sample show an association with cognitive performance, the sample was divided into 3 equally sized groups based on RLT of the layer under study. For each GEE analysis, a variable assigning the specific case to either the first (i.e., lowest RLT) or the third tertile (i.e., highest RLT) was included to focus the analysis only on patients with severe vs little RLT degeneration. Analyses with extreme groups were also controlled for age, educational level, sex, MS subtype, and disease duration. Beta coefficients were not issued due to the statistical nature of the data.

For all analyses, extreme outliers were identified and excluded by generating boxplots of the respective data before the analyses, not displayed here (distance $>3.0 \times \mathrm{IQR}$ ). A $p$ value $\leq 0.05$ was considered the threshold of statistical significance. To correct for multiple testing, the Bonferroni-Holm method was used for all $p$ values per retinal layer.

\section{Data Availability}

Anonymized data will be available from the corresponding author on reasonable request from any qualified investigator.

\section{Results}

Table 1 displays demographic and disease-related information of the examined sample as well as descriptive information on performance in each cognitive test and on thickness of each retinal layer. 
Table 1 Information on Demographic and Diseaserelated Characteristics

\begin{tabular}{ll}
\hline Demographic/disease-related information & Total sample $(\mathbf{N}=\mathbf{5 0})$ \\
\hline Age $(\mathbf{y})^{\mathbf{a}}$ & $47.00 ; 18-59 ; 13.25$ \\
\hline Sex $(\mathbf{n} ; \%$ females) & $40(80.0 \%)$ \\
\hline Education $(\mathbf{n} ; \%)$ & \\
\hline Low & $3(6.0 \%)$ \\
\hline Middle & $10(20.0 \%)$ \\
\hline High & $37(74.0 \%)$ \\
\hline
\end{tabular}

Disease course (n; \%)

\begin{tabular}{ll}
\hline RRMS & $44(88.0 \%)$ \\
\hline SPMS & $6(12.0 \%)$ \\
\hline Age at onset $(\mathbf{y})^{\mathbf{a}}$ & $36.39 \pm 9.15$ \\
\hline${\text { Disease duration }(\mathbf{y})^{\mathbf{a}}}^{\text {EDSS score }}{ }^{\mathbf{a}}$ & $7.34 ; 0.26-28.21 ; 12.1$ \\
\hline
\end{tabular}

\section{Immunotherapy (n; \%)}

\begin{tabular}{ll}
\hline None & $6(12.0)$ \\
\hline First line $^{\mathbf{b}}$ & $27(54.0)$ \\
\hline Second line $^{\mathbf{b}}$ & $17(34.0)$ \\
\hline${\text { Time since last relapse }(\mathbf{m o})^{\mathbf{a}}}$ & $21.93 ; 3.48-159.25 ; 38.81$ \\
\hline
\end{tabular}

Time since last immunotherapy change (mo) ${ }^{\mathrm{a}} \quad 29.32 ; 0.03-159.25 ; 40.12$

\begin{tabular}{ll}
\hline Cognitive tests (raw scores) $^{\mathbf{a}}$ & \\
\hline SDMT & $43.66 \pm 8.62$ \\
\hline VLMT & $55.50 ; 13.00-73.00 ; 16$ \\
\hline BVMT-R & $25.00 ; 0.00-34.00 ; 11.25$ \\
\hline TMT-A & $36.96 ; 17.71-90.74 ; 15.37$ \\
\hline TMT-B & $75.03 ; 33.53-168.94 ; 35.73$
\end{tabular}

\begin{tabular}{ll}
\hline Layer thickness (micrometers) $^{\mathbf{a}}$ & \\
\hline PRNFL & $89.53 \pm 12.61$ \\
\hline mRNFL & $31.33 \pm 4.82$ \\
\hline GCIPL & $65.57 \pm 7.09$ \\
\hline INL & $34.46 \pm 2.55$ \\
\hline BICAMS impaired $(\mathbf{n} ; \%)$ & $18(36 \%)$
\end{tabular}

Abbreviations: BVMT-R = Brief Visuospatial Memory Test-Revised; EDSS = Expanded Disability Status Scale; GCIPL = macular ganglion cell-inner plexiform layer; $I N L=$ macular inner retinal layer; $I Q R=$ interquartile range; $\mathrm{mRNFL}=$ macular retinal nerve fiber layer; $\mathrm{pRNFL}=$ peripapillary retinal nerve fiber layer; RRMS = relapsing-remitting MS; SDMT = Symbol Digit Modalities Test; SPMS = secondary progressive MS; TMT-A/B = Trail Making Test-A/B; VLMT = Verbaler Lern-und Merkfaehigkeitstest.

Missing values: EDSS score $n=1$, time since last relapse $n=1$, time since last immunotherapy change $n=6$.

Raw scores of SDMT, VLMT, BVMT-R are based on achieved number of correct items. Raw scores of TMT-A/B represent the required time to complete the task, measured in seconds.

a Mean \pm SD or median; range; IQR according to nature of the data.

${ }^{\mathrm{b}}$ First line and second line defined according to guidelines by the German Neurological Society (DGN).
RLT in pRNFL, mRNFL, and GCIPL (continuous variables) was each found to be a predictor for the cognitive domain cognitive flexibility (TMT-B; table 2). Patients with lower layer thickness performed worse on TMT-B than patients with higher layer thickness (figure 2 ). Effect sizes $(\beta)$ for pRNFL $(\beta=-0.246)$, mRNFL $(\beta=-0.259)$, and GCIPL $(\beta=$ $-0.199)$ with TMT-B can be classified as small effects. After correcting for multiple testing, however, only thickness of mRNFL remained a significant predictor of TMT-B test performance $(p=0.002)$. Associations of pRNFL, mRNFL, and GCIPL with the remaining cognitive test measures (SDMT, TMT-A, BVMT-R, and VLMT) were not detectable. Moreover, no associations were observed between RLT of INL and any of the examined neuropsychological measures (table 2).

When contrasting extreme groups of RLT (low tertile vs high tertile of each parameter) with each other, the predictive role of mRNFL and GCIPL on TMT-B performance was replicated (table 3). Patients of the lower tertile (mRNFL: range $=$ 19.6-29.1; GCIPL: range $=49.1-63.3$ ) performed worse on TMT-B than patients classified to the higher tertile (mRNFL: range $=33.1-45.5$; GCIPL: range $=68.0-85.5$; see boxplots, figure 3). Associations of GCIPL with VLMT $(p=0.005)$ and with BVMT-R $(p=0.029)$ also became apparent when investigating extreme groups instead of using continuous variables (low tertile: range $=49.1-63.3$; high tertile: range $=$ 68.0-85.5; see boxplots, figure 3). After controlling for multiple testing, the association between mRNFL/GCIPL and TMT-B as well as GCIPL and VLMT remained significant (table 3). No associations were found between SDMT/TMTA and retinal layers, as well as INL and any cognitive measure.

\section{Discussion}

The aim of this study was to investigate whether any of the most relevant OCT metrics in MS could be associated with cognitive test performance and might therefore provide the opportunity to place a focus on patients at risk of developing clinically apparent cognitive dysfunctions in the course of the disease.

Because the analyzed data were obtained from a larger study including an exercise program and EDSS score $\leq 5.0$ as the inclusion criterion, the examined sample represented a patient population with rather mild to moderate clinical manifestations. In addition, the sample was characterized by moderate disease durations and high proportions of patients under any disease-modifying treatment. Regarding demographic measures (age, sex, and educational level), characteristics comparable to previous studies were identified. The observed prevalence rate of $\mathrm{CI}$ as defined by performance in BICAMS (36\%) corresponds to previous studies in mildly affected patients. ${ }^{1,23}$ Data on RLT were also similar to results from earlier studies on patients without medical history of ON measured by an equivalent OCT device. ${ }^{7}$ 
Table 2 GEE Models Predicting Cognitive Test Performance, Separating for Each Pair of RLT (Continuous Variable) as Predictor of Interest and Cognitive Test Outcome as Dependent Variable

\begin{tabular}{|c|c|c|c|c|c|c|c|}
\hline Predictor of interest RLT & AV cognitive test & $\mathbf{n}$ & $\mathrm{n}_{\text {eyes }}$ & B & $\beta$ & $p$ Value & $p^{\prime}$ Value \\
\hline \multirow[t]{5}{*}{ pRNFL } & SDMT & 50 & 79 & 0.0001 & n.a. & 0.115 & 0.912 \\
\hline & VLMT & 50 & 79 & 0.0002 & n.a. & 0.114 & 0.912 \\
\hline & BVMT-R & 50 & 79 & 0.0001 & n.a. & 0.206 & 1.000 \\
\hline & TMT-A & 50 & 79 & -0.0004 & n.a. & 0.088 & 0.792 \\
\hline & TMT-B & 49 & 78 & -0.558 & -0.242 & $0.011 *$ & 0.110 \\
\hline \multirow[t]{5}{*}{ mRNFL } & SDMT & 48 & 77 & 0.0001 & n.a. & 0.474 & 1.000 \\
\hline & VLMT & 48 & 77 & 0.0003 & n.a. & 0.190 & 0.930 \\
\hline & BVMT-R & 48 & 77 & -0.0001 & n.a. & 0.492 & 1.000 \\
\hline & TMT-A & 48 & 77 & -0.001 & n.a. & 0.107 & 0.642 \\
\hline & TMT-B & 47 & 76 & -1.561 & -0.259 & $<0.001 * \star *$ & $0.002^{* *}$ \\
\hline \multirow[t]{5}{*}{ GCIPL } & SDMT & 48 & 77 & 0.0002 & n.a. & 0.086 & 0.344 \\
\hline & VLMT & 48 & 77 & 0.0003 & n.a. & 0.142 & 0.375 \\
\hline & BVMT-R & 48 & 77 & 0.0002 & n.a. & 0.180 & 0.375 \\
\hline & TMT-A & 48 & 77 & -0.001 & n.a. & 0.125 & 0.375 \\
\hline & TMT-B & 47 & 76 & -0.809 & -0.199 & $0.018^{*}$ & 0.144 \\
\hline \multirow[t]{5}{*}{ INL } & SDMT & 48 & 77 & 0.0003 & n.a. & 0.615 & 1.000 \\
\hline & VLMT & 48 & 77 & -0.0003 & n.a. & 0.752 & 1.000 \\
\hline & BVMT-R & 48 & 77 & 0.001 & n.a. & 0.452 & 1.000 \\
\hline & TMT-A & 48 & 77 & -0.0002 & n.a. & 0.882 & 1.000 \\
\hline & TMT-B & 47 & 76 & -1.291 & n.a. & 0.090 & 0.890 \\
\hline
\end{tabular}

Abbreviations: $\mathrm{B}=$ regression coefficient; BVMT-R = Brief Visuospatial Memory Test-Revised; GCIPL = macular ganglion cell-inner plexiform layer; GEE $=$ generalized estimating equation; $I N L=$ macular inner retinal layer; $\mathrm{mRNFL}=$ macular retinal nerve fiber layer; $\mathrm{n}=$ number of cases included; $\mathrm{n}$.a. = not applicable; $n_{\text {eyes }}=$ number of eyes included; $\mathrm{pRNFL}=$ peripapillary retinal nerve fiber layer; $\mathrm{RLT}=$ retinal layer thickness; SDMT = Symbol Digit Modalities Test; TMT-A/B = Trail Making Test-A/B; VLMT = Verbaler Lern-und Merkfaehigkeitstest; $\beta=$ standardized regression coefficient calculated as effect size. $p$ values were corrected with Bonferroni-Holm correction $(p)$ covering all $p$ values per retinal layer (including $p$ values from the analysis of RLT-continuous variable and of RLT-extreme groups, see table 3).

${ }^{\star} p<0.05, * * p<0.01, * \star \star x p<0.001$.

Regarding associations between OCT metrics and cognitive performance, we observed thickness in pRNFL, mRNFL, and GCIPL to be related with TMT-B, which assesses cognitive flexibility as a domain of executive functioning. This relation became evident despite the extensive control of covariates mentioned above. After using Bonferroni-Holm adjustment for multiple testing, the link between mRNFL and TMT-B remained significant. Finding associations between cognitive flexibility as part of executive functioning and RLT matches with studies examining mRNFL and GCIPL that also incorporated tests for executive functioning. ${ }^{14,24,25}$ Cognitive flexibility is considered a complex cognitive ability covering various functions such as working memory, attention, and inhibition operating in a broadly distributed frontoparietal network. ${ }^{26}$ As such, it might be one of the first domains being affected by atrophic processes as manifested in thickness of inner retinal layers, which might therefore serve as a valuable indicator for further extensive and regular neuropsychological testing. Because the applied test for cognitive flexibility, TMT$\mathrm{B}$, is also based on visual capacities, one may wonder whether the effect might have only resulted from potential visual impairments of the participants, rather than CNS atrophy. To rule this out, we excluded eyes with a history of $\mathrm{ON}$ from the analyses beforehand and ensured that participants did not have uncorrected visual ametropia. Furthermore, because no such associations were observed regarding other visually based neuropsychological tests (e.g., SDMT and TMT-A), we assume that the reported relation with cognitive flexibility is not resulting from pure visual impairments.

Furthermore, associations of RLT were neither detected with BICAMS nor with TMT-A when including continuous variables. Although current negative results should be regarded as provisional and require future validation due to the small 
Figure 2 Scatterplots
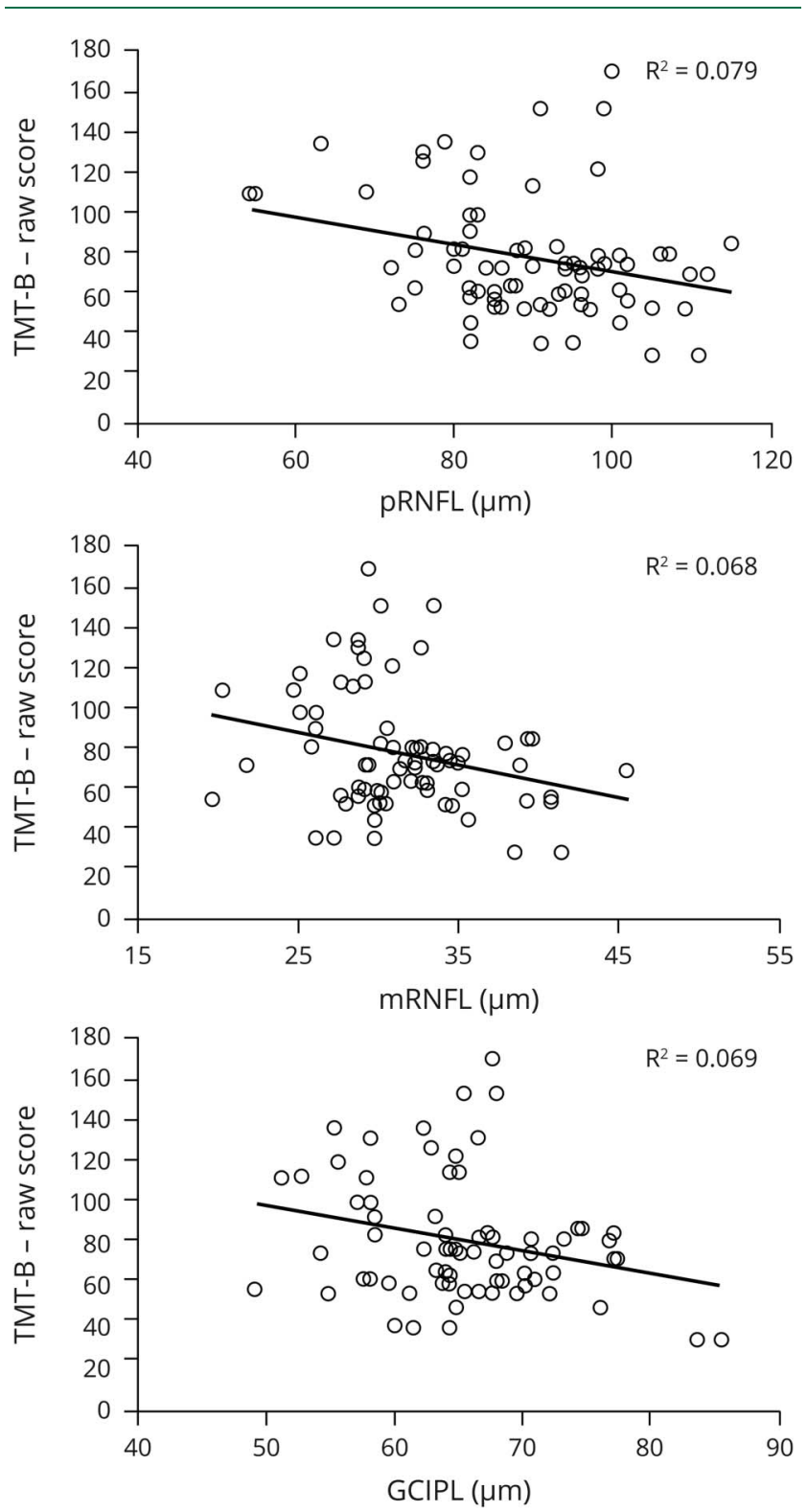

Scatterplots depicting associations between thickness in PRNFL, mRNFL, GCIPL, and cognitive performance in TMT-B. Excluded outliers in each analysis $n=1$. GCIPL = ganglion cell-inner plexiform layer; $\mathrm{mRNFL}=$ macular retinal nerve fiber layer; $\mathrm{pRNFL}$ = peripapillary retinal nerve fiber layer; TMT$\mathrm{B}=$ Trail Making Test-B.

sample size, these results generally confirm reports of latest studies. $^{12,14,15}$ They also signify that the OCT evaluation cannot replace a neuropsychological examination with BICAMS, but might serve as a supplementary method assessing additional factors. This has already been described by Frau and colleagues ${ }^{12}$ who consider OCT (pRNFL) and BICAMS to be instruments investigating different aspects of neurodegeneration in MS because no direct association was found and each instrument correlated with different brain volume regions in MRI. In line with this, our results once more highlight the need of a separate, consecutive, and extensive neuropsychological assessment in patients identified at risk. However, studies examining SDMT as the sole neuropsychological parameter or examining the status of being cognitively impaired as defined by BICAMS (which can be highly influenced by SDMT performance) provide contradictory results reporting associations with RLT. ${ }^{13,22,27-29}$ A reason for the discrepancy to our results might lie in the present study design: the interventional study from which the data were obtained at baseline focused on patients with RRMS and SPMS with at least mild signs of CI in information processing speed (SDMT $\mathrm{z}<-0.5$ and $\mathrm{z}>-3.0$ ). Therefore, inevitably, we were not able to integrate cognitively preserved or extremely impaired patients beyond 3 SDs as defined by SDMT. In consequence, the included SDMT z-scores showed rather little variance, which might have prevented us from detecting an association between RLT and SDMT due to statistical limitations. Apart from that, the discrepancy might also be based on the small sample size of the current study, general differences in the patient characteristics and composition, and the covariates considered. When comparing extreme groups of each retinal thickness regarding cognitive performance, results on pRNFL and INL were not significant. However, we were able to identify thickness of mRNFL to be linked to TMT-B and detected a relation between GCIPL and TMT-B as well as VLMT as one of the BICAMS tests. Before correcting for multiple testing, our results also indicated a potential relation of GCIPL with BVMT-R. Authors who examined a sample of patients with early MS hypothesized that correlations between GCIPL thickness and cognitive disability may become detectable later in the course of the disease or when investigated prospectively. ${ }^{21} \mathrm{We}$ assume this to also be applicable to our results in patients with mild to moderate disability displaying only slight indications for a possible relation between RLT (especially GCIPL) and BICAMS.

Regarding retinal layers, mRNFL and GCIPL turned out to be the main parameters associated ahead of the conventionally examined pRNFL. The INL showed no significant associations with any cognitive test performance. Generally, these results match with the literature, where atrophy affecting axons and neurons in patients with MS (RRMS and SPMS) was found to be reflected by the 3 metrics of pRNFL, GCIPL, and mRNFL, but not by INL. ${ }^{6,7}$ Of those 3 metrics, pRNFL is known to show the highest effect sizes ${ }^{7,30}$ and has been investigated most frequently in relation to cognitive function. ${ }^{11-13,15,21,22,24,27-29,31}$ Recent studies, however, also documented thinning of mRNFL and GCIPL independent of pRNFL in early, most inflammatory, stages of the disease, suggesting that retinal damage could begin from the macular ganglion cells. ${ }^{9,13,32}$ Because GCIPL was therefore reported to provide the advantage to reflect atrophy much earlier than pRNFL, 7 GCIPL might especially be a relevant parameter when investigating OCT metrics as indicator for $\mathrm{CI}$ in patients with mild to moderate clinical manifestations. In line with these neurobiological characteristics, the few studies, that have already investigated mRNFL and GCIPL in relation to cognitive performance, reported associations. ${ }^{13,14,22,24,25,33}$ 
Table 3 GEE Models Predicting Cognitive Test Performance, Separated for Each Pair of RLT (Extreme Groups; Low and High Tertile) as Predictor of Interest and Cognitive Test Outcome as Dependent Variable

\begin{tabular}{|c|c|c|c|c|c|c|c|}
\hline Predictor of interest RLT & AV cognitive test & $\mathbf{n}$ & $\mathrm{n}_{\text {eyes }}$ tertile low; high & B & $\beta$ & $p$ Value & $p^{\prime}$ Value \\
\hline \multirow[t]{5}{*}{ pRNFL extreme groups } & SDMT & 37 & $26 ; 26$ & -0.002 & n.a. & 0.464 & 1.000 \\
\hline & VLMT & 36 & $26 ; 25$ & -0.006 & n.a. & 0.408 & 1.000 \\
\hline & BVMT-R & 36 & $26 ; 25$ & -0.004 & n.a. & 0.472 & 1.000 \\
\hline & TMT-A & 35 & $24 ; 26$ & 0.011 & n.a. & 0.321 & 1.000 \\
\hline & TMT-B & 34 & $25 ; 24$ & 0.034 & n.a. & 0.329 & 1.000 \\
\hline \multirow[t]{5}{*}{ mRNFL extreme groups } & SDMT & 38 & $26 ; 25$ & -2.380 & n.a. & 0.186 & 0.930 \\
\hline & VLMT & 38 & $26 ; 25$ & -5.583 & n.a. & 0.054 & 0.432 \\
\hline & BVMT-R & 38 & $26 ; 25$ & -2.593 & n.a. & 0.340 & 1.000 \\
\hline & TMT-A & 37 & $25 ; 25$ & 6.387 & n.a. & 0.085 & 0.595 \\
\hline & TMT-B & 36 & $25 ; 24$ & 33.682 & n.a. & $<0.001 * \star \star$ & $<0.001 * * *$ \\
\hline \multirow[t]{5}{*}{ GCIPL extreme groups } & SDMT & 36 & $25 ; 25$ & -3.483 & n.a. & 0.058 & 0.300 \\
\hline & VLMT & 36 & $25 ; 25$ & -8.192 & n.a. & $0.005^{* *}$ & $0.045^{*}$ \\
\hline & BVMT-R & 36 & $25 ; 25$ & -5.232 & n.a. & $0.029 * *$ & 0.203 \\
\hline & TMT-A & 35 & $24 ; 25$ & 6.624 & n.a. & 0.050 & 0.300 \\
\hline & TMT-B & 35 & $24 ; 24$ & 26.623 & n.a. & $<0.001 * \star \star$ & $<0.001 * * *$ \\
\hline \multirow[t]{5}{*}{ INL extreme groups } & SDMT & 38 & $28 ; 27$ & -0.338 & n.a. & 0.843 & 1.000 \\
\hline & VLMT & 37 & $28 ; 26$ & 5.518 & n.a. & 0.089 & 0.890 \\
\hline & BVMT-R & 38 & $28 ; 27$ & 0.097 & n.a. & 0.964 & 1.000 \\
\hline & TMT-A & 37 & $27 ; 27$ & -0.788 & n.a. & 0.877 & 1.000 \\
\hline & TMT-B & 37 & $28 ; 26$ & 5.888 & n.a. & 0.393 & 1.000 \\
\hline
\end{tabular}

Abbreviations: $\mathrm{B}=$ regression coefficient; BVMT-R = Brief Visuospatial Memory Test-Revised; $\mathrm{GCIPL}=$ macular ganglion cell-inner plexiform layer; GEE = generalized estimating equation; INL = macular inner retinal layer; $\mathrm{mRNFL}=$ macular retinal nerve fiber layer; $\mathrm{n}=$ number of cases included; $\mathrm{n}_{\text {eyes }}=$ number of eyes included; pRNFL = peripapillary retinal nerve fiber layer; RLT = retinal layer thickness; SDMT = Symbol Digit Modalities Test; TMT-A/B = Trail Making Test-A/B; VLMT = Verbaler Lern-und Merkfaehigkeitstest; $\beta$ = standardized regression coefficient calculated as effect size.

The GEE models of the extreme groups compare the low tertile with the high tertile of each retinal layer.

$p$ values were corrected with Bonferroni-Holm correction $(p)$ covering all $p$ values per retinal layer (including $p$ values from the analysis of RLT-continuous variable and of RLT-extreme groups, see table 2 ).

${ }^{*} p<0.05,{ }^{* *} p<0.01,{ }^{\star \star *} p<0.001$.

By identifying relations of mRNFL (continuous variable and extreme groups) with TMT-B and also of GCIPL (extreme groups) with VLMT and TMT-B, we reinforce the role of macular layers, particularly mRNFL and GCIPL, as potentially suitable markers in associations with $\mathrm{CI}$, especially in patients with mild to moderate disability.

Our study is not without limitations. First, in case of unilateral $\mathrm{ON}$, only the non-ON eye was included in the analyses. However, occurrence of $\mathrm{ON}$ might have an effect on the nonON eye by spreading of inflammation over the optic chiasm. ${ }^{34}$ Second, the analyses were conducted for both MS subtypes RRMS and SPMS together because the research question addressed patients with current mild to moderate neurologic states independent of MS subtype. Yet, to rule out an effect, we included MS subtype as a covariate in all analyses implemented. A more MS subtype-specific characterization of associations between cognitive performance and RLT requires larger homogenous MS cohorts to be analyzed separately. Third, the generalizability of our results is limited by the small sample size and the cross-sectional design, which is why current negative results should be considered provisional. Furthermore, we are aware that the inclusion criterion concerning SDMT z-score resulting from the study design prohibited us from having a control group without CI for comparison. Future research needs to confirm our findings in larger patient populations and longitudinal studies, as well as by examining a control group without $\mathrm{CI}$.

In conclusion, RLT and BICAMS appear to be rather complementary methods in patients with mild to moderate clinical deficits because no associations were observed for SDMT and BVMT-R with RLT when correcting for multiple testing. However, because of the detected relation with cognitive 

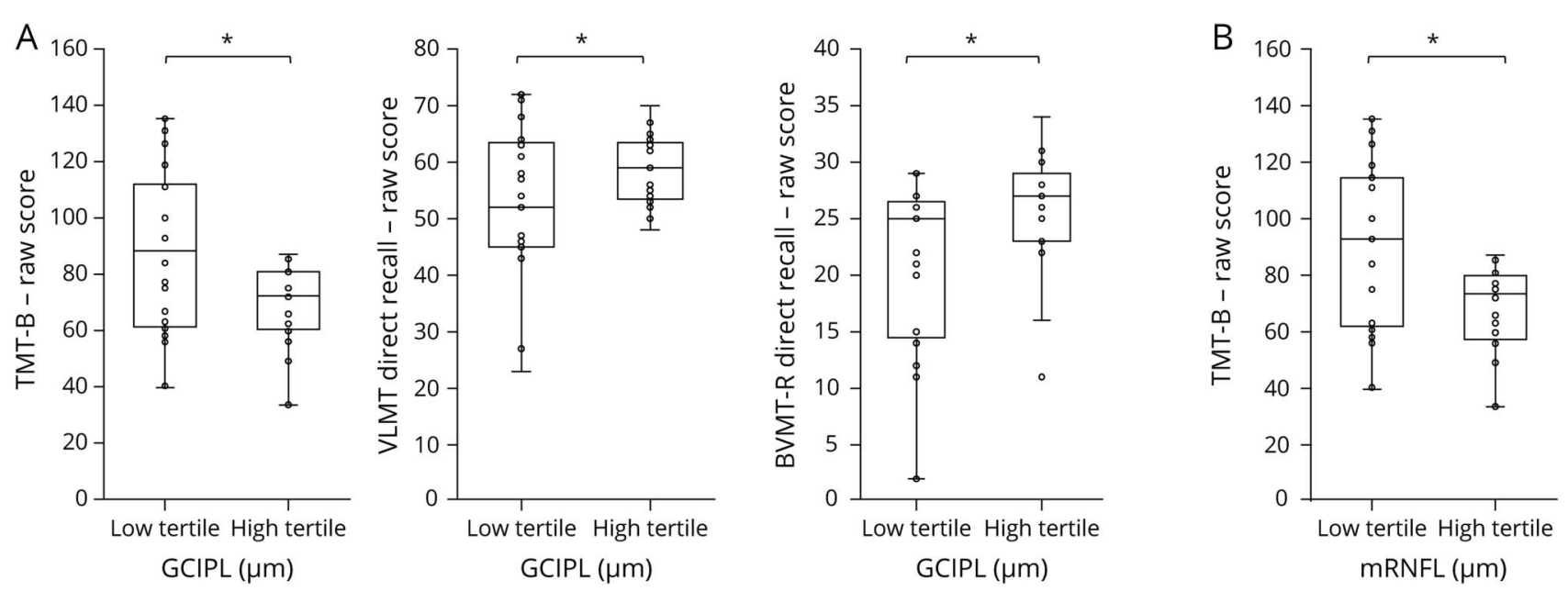

Boxplots and point clouds depicting raw scores on cognitive performance per RLT extreme group. (A) Cognitive performance in Trail Making Test-B (TMT-B), Verbaler Lern-und Merkfaehigkeitstest (VLMT), and Brief Visuospatial Memory Test-Revised (BVMT-R), each divided into the low tertile and high tertile of retinal layer thickness (RLT) of macular ganglion cell-inner plexiform layer (mGCIPL). (B) Cognitive performance in Trail Making Test-B (TMT-B) divided into low tertile and high tertile of retinal layer thickness (RLT) of macular ganglion cell-inner plexiform layer (mGCIPL) (all analyses including TMT-B: excluded outliers n

=2). *Raw scores in designated cognitive test differ significantly between low and high tertile of RLT referring to uncorrected $p$ values.

flexibility, thickness in mRNFL and GCIPL may bear the potential to become a marker for further extensive neuropsychological testing when showing abnormalities. Because neuropsychological assessments (e.g., BICAMS) are still not commonly applied within the diagnostic process and monitoring of patients with MS, OCT may offer the opportunity to identify patients at risk for $\mathrm{CI}$ as early as possible in a costefficient and feasible way. This way, OCT results might provide the impulse to initiate extensive neuropsychological evaluations and regular monitoring assessments where advisable.

\section{Acknowledgment}

The authors thank all patients for participating in this study and all colleagues from the Department of Neurology at the HHU, especially Mrs. Eva Cohn for performing a large part of the OCT examinations and Mrs. Anja Felten, Mrs. Dagmar Schulte, and all physicians for taking care of the participating patients. They also thank Carolin Balloff, MSc (Heinrich Heine University, Düsseldorf) for her valuable support in data collection.

\section{Study Funding}

This research was financially supported by Teva. The funders had no influence on the design and conduct of the study; collection, management, analysis, and interpretation of the data; preparation, review, or approval of the manuscript; and decision to submit the manuscript for publication.

\section{Disclosure}

S.J. Baetge reports no disclosures. M. Dietrich received speaker honoraria from Novartis and Merck. M. Filser, A. Renner, N. Stute, M. Gasis, M. Weise, and K. Lepka report no disclosures. J. Graf received travel/meeting/accommodation reimbursements from Biogen, Merck Serono, SanofiGenzyme, and Grifols and a Research Fellowship from the Deutsche Forschungsgemeinschaft (project number 438899010). N. Goebels has received honoraria for speaking at scientific meetings, serving at scientific advisory boards, travel, and/or research support from Biogen, BMBF, HHUForschungskommission, iBrain, International Progressive MS Alliance, Novartis, Roche, Sanofi-Genzyme, and Wellcome Trust. H.-P. Hartung reports fees for consulting, speaking, and serving on steering committees from Bayer HealthCare, Biogen, GeNeuro, MedImmune, Merck, Novartis, Opexa, Receptos Celgene, Roche, Sanofi Genzyme, CSL Behring, Octapharma, and Teva, with approval by the Rector of Heinrich-Heine-University. O. Aktas received support from the German Ministry for Education and Research (BMBF) as part of the "German Competence Network Multiple Sclerosis" (KKNMS; FKZ01GI1602B), as well as fees from Almirall, Bayer HealthCare, Biogen, Merck, Roche, Sanofi-Genzyme, and Teva for speaker services and advisory boards, and research grants from Biogen, Merck, and Sanofi-Genzyme. S. Meuth receives honoraria for lecturing and travel expenses for attending meetings from Almirall, Amicus Therapeutics Germany, Bayer HealthCare, Biogen, Celgene, Diamed, Genzyme, MedDay Pharmaceuticals, Merck Serono, Novartis, Novo Nordisk, ONO Pharma, Roche, Sanofi-Aventis, Chugai Pharma, QuintilesIMS, and Teva. His research is funded by the German Ministry for Education and Research (BMBF), Bundesinstitut für Risikobewertung (BfR), Deutsche Forschungsgemeinschaft (DFG), Else Kröner Fresenius Foundation, Gemeinsamer Bundesausschuss (G-BA), German Academic Exchange Service, Hertie Foundation, Interdisciplinary Center for Clinical Studies (IZKF) Muenster, 
German Foundation Neurology and Alexion, Almirall, Amicus Therapeutics Germany, Biogen, Diamed, Fresenius Medical Care, Genzyme, HERZ Burgdorf, Merck Serono, Novartis, ONO Pharma, Roche, and Teva. P. Albrecht has received compensation for serving on scientific advisory boards for Allergan, Celgene, Ipsen, Merck, Merz, Novartis, Roche, and Biogen; he received speaker honoraria and travel support from Novartis, Teva, Biogen, Merz Pharmaceuticals, Ipsen, Allergan, Bayer and HealthCare; he received research support from Allergan, Biogen, Celgene, Ipsen, Novartis, Teva, Merck, Merz Pharmaceuticals, and Roche. I.-K. Penner has received honoraria for speaking at scientific meetings, serving at scientific advisory boards, and consulting activities from Adamas Pharma, Almirall, Bayer Pharma, Biogen, Celgene, Desitin, Genzyme, Janssen, Merck, Novartis, Roche, and Teva; she has received research support from the German MS Society, Celgene, Novartis, Roche, and Teva. Go to Neurology.org/NN for full disclosures.

\section{Publication History}

Received by Neurology: Neuroimmunology \& Neuroinflammation December 9, 2020. Accepted in final form April 13, 2021.

Appendix Authors

\begin{tabular}{|c|c|c|}
\hline Name & Location & Contribution \\
\hline $\begin{array}{l}\text { Sharon } \\
\text { Jean } \\
\text { Baetge, } \\
\text { MSc }\end{array}$ & $\begin{array}{l}\text { Cogito Center for Applied } \\
\text { Neurocognition and } \\
\text { Neuropsychological } \\
\text { Research, Düsseldorf }\end{array}$ & $\begin{array}{l}\text { Data acquisition and } \\
\text { management, literature } \\
\text { research, statistical analysis } \\
\text { and interpretation, } \\
\text { manuscript drafting, and } \\
\text { critical revision and approval } \\
\text { of the final version of the } \\
\text { manuscript }\end{array}$ \\
\hline
\end{tabular}

\begin{tabular}{|c|c|c|}
\hline $\begin{array}{l}\text { Michael } \\
\text { Dietrich, } \\
\text { PhD }\end{array}$ & $\begin{array}{l}\text { Department of Neurology, } \\
\text { Medical Faculty, Heinrich } \\
\text { Heine University, Düsseldorf }\end{array}$ & $\begin{array}{l}\text { Literature research, statistical } \\
\text { interpretation, manuscript } \\
\text { drafting, and critical revision } \\
\text { and approval of the final } \\
\text { version of the manuscript }\end{array}$ \\
\hline $\begin{array}{l}\text { Melanie } \\
\text { Filser, MSc }\end{array}$ & $\begin{array}{l}\text { Cogito Center for Applied } \\
\text { Neurocognition and } \\
\text { Neuropsychological } \\
\text { Research, Düsseldorf }\end{array}$ & $\begin{array}{l}\text { Data acquisition and } \\
\text { management and critical } \\
\text { revision and approval of the } \\
\text { final version of the } \\
\text { manuscript }\end{array}$ \\
\hline $\begin{array}{l}\text { Alina } \\
\text { Renner, } \\
\text { MSc }\end{array}$ & $\begin{array}{l}\text { Cogito Center for Applied } \\
\text { Neurocognition and } \\
\text { Neuropsychological } \\
\text { Research, Düsseldorf }\end{array}$ & $\begin{array}{l}\text { Data acquisition and } \\
\text { management and critical } \\
\text { revision and approval of the } \\
\text { final version of the } \\
\text { manuscript }\end{array}$ \\
\hline $\begin{array}{l}\text { Nathalie } \\
\text { Stute, MSc }\end{array}$ & $\begin{array}{l}\text { Cogito Center for Applied } \\
\text { Neurocognition and } \\
\text { Neuropsychological } \\
\text { Research, Düsseldorf }\end{array}$ & $\begin{array}{l}\text { Data acquisition and critical } \\
\text { revision and approval of the } \\
\text { final version of the } \\
\text { manuscript }\end{array}$ \\
\hline $\begin{array}{l}\text { Marcia } \\
\text { Gasis, MSc }\end{array}$ & $\begin{array}{l}\text { Department of Neurology, } \\
\text { Medical Faculty, Heinrich } \\
\text { Heine University, Düsseldorf }\end{array}$ & $\begin{array}{l}\text { Data acquisition and } \\
\text { management and critical } \\
\text { revision and approval of the } \\
\text { final version of the } \\
\text { manuscript }\end{array}$ \\
\hline $\begin{array}{l}\text { Margit } \\
\text { Weise, MSc }\end{array}$ & $\begin{array}{l}\text { Department of Neurology, } \\
\text { Medical Faculty, Heinrich } \\
\text { Heine University, Düsseldorf }\end{array}$ & $\begin{array}{l}\text { Data acquisition, statistical } \\
\text { interpretation, and critical } \\
\text { revision and approval of the } \\
\text { final version of the } \\
\text { manuscript }\end{array}$ \\
\hline
\end{tabular}

Appendix (continued)

\begin{tabular}{lll}
\hline Name & Location & Contribution \\
\hline $\begin{array}{lll}\text { Klaudia } \\
\text { Lepka, PhD }\end{array}$ & $\begin{array}{l}\text { Department of Neurology, } \\
\text { Medical Faculty, Heinrich } \\
\text { Heine University, Düsseldorf }\end{array}$ & $\begin{array}{l}\text { Data acquisition and } \\
\text { management and critical } \\
\text { revision and approval of the } \\
\text { final version of the } \\
\text { manuscript }\end{array}$ \\
\hline
\end{tabular}
Medical Faculty, Heinrich revision and approval of the Heine University, Düsseldorf final version of the manuscript

\begin{tabular}{lll}
\hline Norbert & Department of Neurology, & Data acquisition and critical \\
Goebels, & Medical Faculty, Heinrich & revision and approval of the \\
MD & Heine University, Düsseldorf & final version of the
\end{tabular}
manuscript

\begin{tabular}{ll}
\hline Hans-Peter & Department of Neurology, \\
Hartung, & Medical Faculty, Heinrich \\
MD & Heine University, Düsseldorf
\end{tabular}

Study design and conceptualization and critical revision and approval of the final version of the manuscript

\begin{tabular}{ll}
\hline Orhan & Department of Neurology, \\
Aktas, MD & Medical Faculty, Heinrich \\
& Heine University, Düsseldorf
\end{tabular}

Data acquisition and critical revision and approval of the final version of the manuscript

\begin{tabular}{lll}
\hline $\begin{array}{l}\text { Sven } \\
\text { Meuth, } \\
\text { MD/PhD }\end{array}$ & $\begin{array}{l}\text { Department of Neurology, } \\
\text { Medical Faculty, Heinrich } \\
\text { Heine University, Düsseldorf }\end{array}$ & $\begin{array}{l}\text { Statistical interpretation and } \\
\text { critical revision and approval } \\
\text { of the final version of the } \\
\text { manuscript }\end{array}$ \\
\hline $\begin{array}{l}\text { Philipp } \\
\text { Albrecht, } \\
\text { MD }\end{array}$ & $\begin{array}{l}\text { Department of Neurology, } \\
\text { Medical Faculty, Heinrich } \\
\text { Heine University, Düsseldorf }\end{array}$ & $\begin{array}{l}\text { Literature research, data } \\
\text { acquisition, statistical } \\
\text { interpretation, and critical } \\
\text { revision and approval of the } \\
\text { final version of the } \\
\text { manuscript }\end{array}$ \\
$\begin{array}{lll}\text { Iris- } \\
\text { Katharina } \\
\text { Penner, } \\
\text { PhD }\end{array}$ & $\begin{array}{l}\text { Neurocognition and } \\
\text { Neuropsychological }\end{array}$ & $\begin{array}{l}\text { Literature research, study } \\
\text { design and conceptualization, } \\
\text { acquisition of funding, data } \\
\text { acquisition, statistical }\end{array}$ \\
& Research, Düsseldorf & $\begin{array}{l}\text { interpretation, manuscript } \\
\text { drafting, and critical revision } \\
\text { and approval of the final } \\
\text { version of the manuscript }\end{array}$ \\
& &
\end{tabular}

\section{References}

1. Ruano L, Portaccio E, Goretti B, et al. Age and disability drive cognitive impairment in multiple sclerosis across disease subtypes. Mult Scler J. 2017;23:1258-1267.

2. Amato MP, Portaccio E, Goretti B, et al. Relevance of cognitive deterioration in early relapsing-remitting MS: a 3-year follow-up study. Mult Scler J. 2010;16:1474-1482.

3. Langdon DW. Cognition in multiple sclerosis. Curr Opin Neurol. 2011;24:244-249.

4. Mollison D, Sellar R, Bastin M, et al. The clinico-radiological paradox of cognitive function and MRI burden of white matter lesions in people with multiple sclerosis: a systematic review and meta-analysis. PLoS One. 2017;12:e0177727.

5. Uher T, Krasensky J, Sobisek L, et al. Cognitive clinico-radiological paradox in early stages of multiple sclerosis. Ann Clin Transl Neurol. 2018;5:81-91.

6. Albrecht $P$, Ringelstein $M$, Müller AK, et al. Degeneration of retinal layers in multiple sclerosis subtypes quantified by optical coherence tomography. Mult Scler J. 2012;18:1422-1429.

7. Petzold A, Balcer L, Calabresi PA, et al. Retinal layer segmentation in multiple sclerosis: a systematic review and meta-analysis. Lancet Neurol. 2017;16:797-812.

8. Dörr J, Wernecke KD, Bock M, et al. Association of retinal and macular damage with brain atrophy in multiple sclerosis. PLoS One. 2011;6:2-7.

9. Saidha S, Al-Louzi O, Ratchford JN, et al. Optical coherence tomography reflects brain atrophy in multiple sclerosis: a four-year study. Ann Neurol. 2015;78:801-813.

10. Gandhi S, Hagemeier J, Chandra A, et al. Optical coherence tomography is associated with development of brain atrophy in relapsing-remitting multiple Sclerosis : a longitudinal 5-year follow-. Ann Neurol. 2016;78:801-813.

11. Sedighi B, Shafa MA, Abna Z, et al. Association of cognitive deficits with optical coherence tomography changes in multiple sclerosis patients. J Mult Scler. 2014;1:1-4.

12. Frau J, Fenu G, Signori A, et al. A cross-sectional and longitudinal study evaluating brain volumes, RNFL, and cognitive functions in MS patients and healthy controls. BMC Neurol. 2018;18:1-7. 
13. Petracca M, Sumowski J, Fabian M, et al. Looking into cognitive impairment in primary-progressive multiple sclerosis. Eur J Neurol. 2018;25:192-195.

14. Nguyen J, Rothman A, Fitzgerald K, et al. Visual pathway measures are associated with neuropsychological function in MS. Curr Eye Res. 2018;43:941-948.

15. Naseer MA, Fathi S, Labib DM, et al. Early detection of cognitive dysfunction in patients with multiple sclerosis: implications on outcome. Brain Impair. 2019;21:1-9.

16. Langdon $\mathrm{D}$, Amato $\mathrm{M}$, Boringa J, et al. Recommendations for a Brief international cognitive assessment for multiple sclerosis (BICAMS). Mult Scler J. 2012;18:891-898.

17. Tewarie P, Balk L, Costello F, et al. The OSCAR-IB consensus criteria for retinal OCT quality assessment. PLoS One. 2012;7:1-7.

18. Cruz-Herranz A, Balk LJ, Oberwahrenbrock T, et al. The APOSTEL recommendations for reporting quantitative optical coherence tomography studies. Neurology. 2016;86:2303-2309.

19. Schippling S, Balk LJ, Costello F, et al. Quality control for retinal OCT in multiple sclerosis: validation of the OSCAR-IB criteria. Mult Scler J. 2015;21:163-170.

20. Balk LJ, Tewarie P, Killestein J, et al. Disease course heterogeneity and OCT in multiple sclerosis. Mult Scler J. 2014;20:1198-1206.

21. El Ayoubi NK, Ghassan S, Said M, et al. Retinal measures correlate with cognitive and physical disability in early multiple sclerosis. J Neurol. 2016;263:2287-2295.

22. Birkeldh U, Manouchehrinia A, Hietala MA, et al. The temporal retinal nerve fiber layer thickness is the most important optical coherence tomography estimate in multiple sclerosis. Front Neurol. 2017;8:675.

23. Planche V, Gibelin M, Cregut D, et al. Cognitive impairment in a population-based study of patients with multiple sclerosis: differences between late relapsing-remitting, secondary progressive and primary progressive multiple sclerosis. Eur J Neurol. 2016; 23:282-289.

24. Coric D, Balk LJ, Verrijp M, et al. Cognitive impairment in patients with multiple sclerosis is associated with atrophy of the inner retinal layers. Mult Scler. 2018;24: $158-166$.
25. Stellmann JP, Cetin H, Young KL, et al. Pattern of gray matter volumes related to retinal thickness and its association with cognitive function in relapsing-remitting MS Brain Behav. 2017;7:1-14.

26. Dajani DR, Uddin LQ. Demystifying cognitive flexibility: implications for clinical and developmental neuroscience. Trends Neurosci. 2019;38:571-578.

27. Bsteh G, Hegen H, Teuchner B, et al. Peripapillary retinal nerve fibre layer as measured by optical coherence tomography is a prognostic biomarker not only for physical but also for cognitive disability progression in multiple sclerosis. Mult Scler J 2019;25:196-203.

28. Toledo J, Sepulcre J, Salinas-Alaman A, et al. Retinal nerve fiber layer atrophy is associated with physical and cognitive disability in multiple sclerosis. Mult Scler. 2008 14:906-912.

29. Birkeldh U, Manouchehrinia A, Hietala MA, et al. Retinal nerve fiber layer thickness associates with cognitive impairment and physical disability in multiple sclerosis. Mult Scler Relat Disord. 2019;36:101414.

30. Alonso R, Gonzalez-Moron D, Garcea O. Optical coherence tomography as a biomarker of neurodegeneration in multiple sclerosis: a review. Mult Scler Relat Disord. 2018;22:77-82.

31. Yurtoğullari Ş, Taşkapilioğlu Ö, Öztürk B, et al. Comparison of brain atrophy, cognition and optical coherence tomography results between multiple sclerosis patients and healthy controls. Noropsikiyatri Ars. 2018;55:3-8.

32. Pietroboni AM, Dell'Arti L, Caprioli M, et al. The loss of macular ganglion cells begins from the early stages of disease and correlates with brain atrophy in multiple sclerosis patients. Mult Scler J. 2019;25:31-38.

33. Esmael A, Elsherif M, Abdelsalam M, et al. Retinal thickness as a potential biomarker of neurodegeneration and a predictor of early cognitive impairment in patients with multiple sclerosis. Neurol Res. 2020:1-11.

34. Petzold A, de Boer JF, Schippling S, et al. Optical coherence tomography in multiple sclerosis: a systematic review and meta-analysis. Lancet Neurol. 2010;9:921-932. 


\section{Neurology \\ Neuroimmunology \& Neuroinflammation}

\section{Association of Retinal Layer Thickness With Cognition in Patients With Multiple Sclerosis \\ Sharon Jean Baetge, Michael Dietrich, Melanie Filser, et al. \\ Neurol Neuroimmunol Neuroinflamm 2021;8; \\ DOI 10.1212/NXI.0000000000001018}

This information is current as of May 27, 2021

\section{Updated Information \& Services}

References

Subspecialty Collections

Permissions \& Licensing

\section{Reprints}

including high resolution figures, can be found at: http://nn.neurology.org/content/8/4/e1018.full.html

This article cites 33 articles, 0 of which you can access for free at: http://nn.neurology.org/content/8/4/e1018.full.html\#\#ref-list-1

This article, along with others on similar topics, appears in the following collection(s):

Multiple sclerosis

http://nn.neurology.org//cgi/collection/multiple_sclerosis

Neuropsychological assessment

http://nn.neurology.org//cgi/collection/neuropsychological_assessment

Information about reproducing this article in parts (figures,tables) or in its entirety can be found online at:

http://nn.neurology.org/misc/about.xhtml\#permissions

Information about ordering reprints can be found online:

http://nn.neurology.org/misc/addir.xhtml\#reprintsus

Neurol Neuroimmunol Neuroinflamm is an official journal of the American Academy of Neurology.

Published since April 2014, it is an open-access, online-only, continuous publication journal. Copyright

Copyright (C) 2021 The Author(s). Published by Wolters Kluwer Health, Inc. on behalf of the American

Academy of Neurology.. All rights reserved. Online ISSN: 2332-7812.

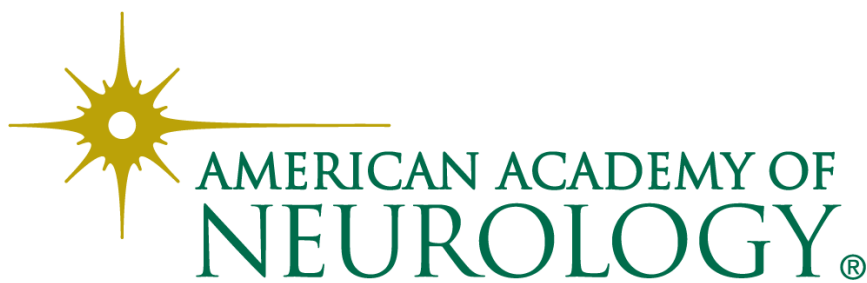

